\title{
The effect of smoking on back pain intensity in rehabilitated patients treated conservatively and surgically for discopathy
}

\author{
Kamil Koszela ${ }^{1,2, A-E \oplus}$, Marta Woldańska-Okońska', ${ }^{1, \mathrm{CE}-\mathrm{F} \oplus}$ \\ ${ }^{1}$ Department of Rehabilitation and Physical Medicine, Medical University, Łódź, Poland \\ ${ }^{2}$ Neuroorthopedics and Neurology Clinic and Polyclinic, National Institute of Geriatrics, Rheumatology and \\ Rehabilitation, Warsaw, Poland \\ A - Research concept and design, B - Collection and/or assembly of data, C - Data analysis and interpretation, \\ $D$ - Writing the article, $E$ - Critical revision of the article, $F$ - Final approval of article \\ Koszela K, Woldańska-Okońska M. The effect of smoking on back pain intensity in rehabilitated patients treated conservatively and surgically \\ for discopathy. Ann Agric Environ Med. 2021; 28(1): 179-182. doi: 10.26444/aaem/123871
}

\begin{abstract}
Introduction. Back pain is now a very common phenomenon. It is caused by various pathologies in the area of the motor unit of the spine. These changes can cause pressure on the nerve structures within the spinal canal, resulting in various ailments. Pain is the most common symptom. In most cases, patients are qualified for conservative management. In the case of neurological deficits, the patient is qualified for spinal surgery. Unfortunately, surgical treatment is not always $100 \%$ effective therapy method. Moreover, many external factors, such as smoking for instance, can affect the process of tissue healing and decide on the time of recovery.

Objective. The aim of the study was to assess the impact of smoking on back pain intensity in rehabilitated patients with discopathy treated conservatively and surgically.

Materials and method. The study included 41 patients after surgical treatment ( 9 smokers) and 96 patients (20 smokers) undergoing conservative therapy for back pain due to discopathy. All patients underwent a multidirectional rehabilitation programme at the Department of Rehabilitation and Physical Medicine of the Medical University in Łódź.

Results. The Laitinen scale was used to assess the patients' pain. Rehabilitation of patients with back pain due to discopathy had a significant analgesic effect ( $p<0.0001)$. Furthermore, there was observed a statistically significant effect of smoking on the level of pain intensity on the Laitinen scale in the group of patients who underwent surgery $(p<0.0469)$. The smokers operated on had significantly worse results.

Conclusions. 1) Complex rehabilitation of patients with back syndrome pain due to discopathy demonstrated significant analgesic effectiveness. 2) Smoking significantly worsens the results of the therapy in patients who underwent surgery.
\end{abstract}

\section{Key words}

rehabilitation, back pain, cigarette smoke, discopathy, spine surgery

\section{INTRODUCTION}

Pain is the most common symptom resulting from an ongoing disease process in the spine. It is often associated with so-called discosis, i.e. degenerative changes in the intervertebral discs, which are the basis for intervertebral disc displacement, predisposing to the formation of herniated nucleus pulposus (HNP), and even to the detachment of its fragment (sequestration) [1].

Research studies have shown that everyone over the age of 30 have degenerative changes within the intervertebral disc, associated with, among others, atrophy of intervertebral disc vascularization at the age of $2-4$ years $[1,2]$. The main reason for the early formation of discosis is associated with the upright position of the body, causing pressure on the intervertebral disc and gradual atrophy of blood vessels within it. Thus, the disc becomes the largest uniform structure of the body which does not have its own blood system. In this situation, the disc is nourished by diffusion, which is impaired, among others, due to a sedentary lifestyle

Address for correspondence: Kamil Koszela, Department of Rehabilitation and Physical Medicine, Medical University, Łódź, Poland

E-mail:kamil.aikido@interia.pl

Received: 25.03.2020; accepted: 09.06.2020; first published: 17.06.2020 with prolonged remaining in an unchanged position, which causes disorders of fluid flow within it [1].

Different spine sections are subject to intervertebral disc diseases with different frequencies. Statistical data show that most often these pathologies occur in the lumbosacral segment - in $62 \%$ of patients, in the cervical segment in $36 \%$ and in the thoracic only in $2 \%$ of cases [1].

Discopathic changes can cause pressure on nerve structures within the spinal canal, generating various ailments. In most cases, patients are qualified for conservative treatment. In the case of neurological loss symptoms, the patients are qualified for spinal surgery $[1,3]$.

The main purpose of the surgery is to remove a fragment of the disc and to decompress the nerve structures that are most often compressed by HNP. As a result, two significant changes occur within the motor segment, including loss of height and relaxation of the intervertebral space due to the loss of intervertebral disc tissue, which may cause instability and scarring (adhesions) within the surgical site. The more extensive the surgical procedure, the greater the risk of postoperative complications, including a longer tissue healing process, especially in the case of blood vessel damage, e.g. in the course of diabetes or smoking. These factors are also risk factors that accelerate the process of the intervertebral disc degeneration [1]. 
Recent data have shown that despite a systematic reduction in the frequency of smoking, every fourth Polish citizen (every fifth female and every third male) is a smoker [4].

In studies, former smokers had a higher prevalence of low back pain compared with never smokers. However, lower prevalence of low back pain was observed in current smokers. In cohort studies, both former and current smokers had an increased incidence of low back pain compared with never smokers. The association between current smoking and the incidence of low back pain was stronger in adolescents than in adults [5].

The aim of the study was to assess the impact of smoking on back pain intensity in rehabilitated patients with discopathy treated conservatively and surgically.

\section{MATERIALS AND METHOD}

The study included 137 patients aged 19-89 years, mean age 62 years: 77 women and 60 men, with women constituting the majority, i.e. $56 \%$ of the total. The subjects were hospitalized in the Department of Rehabilitation and Physical Medicine of the Medical University of Łódż (from 1 January 2014 - 31 December 2016) due to back pain.

The main symptom reported by the patients was back pain due to discopathy, i.e. protrusion, herniated nucleus pulposus (HNP) and sequestration. These changes were confirmed by spine magnetic resonance imaging and computed tomography. Patients were examined and the medical history collected upon admission to the Department.

Inclusion criteria for the study group were:

- back pain syndrome caused by discopathy and confirmed by MRI or CT.

Exclusion criteria: - back pain syndrome without discopathy in MRI or CT.

Some patients $(n=41)$ underwent spinal surgery before admission to the Department due to back pain in the course of discopathy. Twenty patients (49\%) underwent fusion surgery: ACIF (Anterior Cervical Interbody Fusion) or PLIF (Posterior Lumbar Interbody Fusion). The remaining 21 patients (51\%) underwent: surgery involving the removal of herniated disc or a sequester without fusion. These were discectomies and microdiscectomies [1].

The rest of the patients $(n=96)$ were treated only with conservative methods. After admission to the Department, all patients $(n=137)$ were qualified for treatment with kinesi- and physical therapy rehabilitation for 6 days a week. Kinesitherapy is based on isometric exercises, active loadfree, balance and loosening and relaxation exercises. NDTBobath and McKenzie methods were also used in some patients. Physical therapy was based on the application of ultrasound, magnetic field, laser-, cryo- and electrotherapy. Gait, re-education exercises were also used.

In the analyzed group, the average hospitalization period was 29 days. The shortest hospital stay was 17 days and the longest 51 . This difference was related to the fact that patients in whom insufficient improvement had been observed had a prolonged rehabilitation period, especially those whose back pain syndrome was of a more chronic nature (lasted longer).

Twenty-nine (21\%) hospitalized patients smoked cigarettes, including 9 surgically treated (the average hospitalization period was 30 days, the shortest - 23 days and the longest 44. Two patients presented with arterial hypertension and one with type 2 diabetes mellitus.

Twenty patients were treated only with conservative methods (average hospitalization period - 28 days, the shortest hospital stay - 21 days, and the longest -42 ). Three patients had arterial hypertension, 2 - type 2 diabetes mellitus, and 1 - ischemic heart disease. Smokers smoked an average of one packet per day for a minimum of 5 years; they also smoked during hospitalization.

The Laitinen scale analyzing pain intensity and frequency, use of analgesics and limitation of motor activity was used for clinical assessment of the level of spinal pain. The maximum value on this scale is 16 and the minimum value -0 [6].

The obtained results were organized in a summary sheet and subjected to statistical analysis. During the rehabilitation programme, no complications were observed that would result in discontinuation of the therapy. All patients were discharged in good general condition and referred for further outpatient treatment.

Statistical analysis was performed using STATISTICA version 12.5 and Numbers version 10.0. Mann-Whitney $U$ test and Wilcoxon signed-rank test were also used. Value of $\mathrm{p}<0.05$ was considered statistically significant.

The study was approved by the Local Bioethics Committee (No: RNN/208/16/KE).

\section{RESULTS}

After rehabilitation of patients operated for back pain due to discopathy, a significant improvement was observed in their clinical condition $(\mathrm{p}<0.0001)$.

The presented Tables demonstrate the results of the effect of smoking on the level of pain intensity in the Laitinen scale in the entire study group, and in the group of patients with back pain treated surgically or non-surgically due to discopathy.

Table 1. Laitinen score assessment before and after rehabilitation in the group of patients subjected to surgery

\begin{tabular}{lcccc}
\hline & $\begin{array}{c}\text { Before } \\
\text { rehabilitation } \\
\text { median (IQR) }\end{array}$ & $\begin{array}{c}\text { After } \\
\text { rehabilitation } \\
\text { median (IQR) }\end{array}$ & $\begin{array}{c}\text { Delta } \\
\text { median (IQR) }\end{array}$ & p \\
\hline Laitinen Scale & $8.0(7.0-10.0)$ & $4.0(3.0-5.0)$ & $-4.0(-5.0$ do -3.0) & $<0.0001$ \\
\hline
\end{tabular}

Table 2. Laitinen score assessment before and after rehabilitation in the entire group, in the group of surgically and non-surgically treated patients

\begin{tabular}{|c|c|c|c|c|c|}
\hline \multirow{3}{*}{ Group } & \multicolumn{5}{|c|}{ Delta Laitinen Scale } \\
\hline & \multicolumn{2}{|c|}{ Smokers } & \multicolumn{2}{|c|}{ Non-smokers } & \multirow[b]{2}{*}{$\mathrm{p}$} \\
\hline & median & IQR & median & IQR & \\
\hline Total group & 4.0 & -6.0 to -3.0 & 4.0 & -6.0 to -3.0 & 0.8673 \\
\hline Non-operated group & 6.0 & -7.0 to -4.0 & 5.0 & -6.0 to -4.0 & 0.3258 \\
\hline Operated group & 3.0 & -4.0 to -3.0 & 4.0 & -6.5 to -3.0 & 0.0469 \\
\hline
\end{tabular}

\section{DISCUSSION}

Back pain syndrome affects a very large social group and is often referred to as a 'civilization disease' [3]. The most common symptom with which a patient reports to a physician 
is back pain. This type of ailment is usually not a very serious condition and in most cases it can be treated conservatively with the help of pharmacotherapy, physiotherapy and change in lifestyle, although some patients require surgery. It is assumed that $1-10 \%$ of patients require surgical intervention $[1,7]$.

Because the problem affects a large social group it is a huge financial burden for the State, which results both from performing medical procedures and from high absenteeism in the workplace and earlier decision of incapacity for work. A high incidence of intervertebral disc pathologies means that they have a large impact on the medical, insurance and public health sectors.

It is very important to recognize the causes of the ailment and to implement appropriate causal treatment and not to focus only on the symptomatic treatment itself. Quick and reliable diagnosis of spinal pain syndrome based on the patient's clinical examination and suitable diagnostic imaging allows for appropriate treatment. Thus, the patient returns faster to fitness and professional activity.

The treatment of back pain syndrome caused by discopathy depends primarily on the symptoms presented by the patient. In the absence of neurological symptoms, the patient will first be qualified for conservative treatment in the form of pharmacotherapy, physiotherapy based on physical therapy and kinesitherapy, as well as on education. Koszela et al. (2017) showed the effectiveness of multidirectional rehabilitation based on the use of physical therapy and kinesitherapy to reduce back pain in patients with pain syndrome caused by the presence of a herniated nucleus pulposus [8].

Some patients with discopathy require surgical intervention. This is especially the case when no improvement is observed after conservative treatment. Of course, when signs of neurological deficiency occur, which are an absolute indication for surgery, the surgical method should be the basic form of therapy (including the need to continue treatment on an outpatient or inpatient health care basis) $[1,9]$. The appropriate qualification of the patient for proper surgical method is a very important issue. Depending on the patient's clinical condition, type of pathology and anatomical conditions, an individualized form of surgical treatment should be chosen $[1,3,9]$.

Every surgical procedure, including spine surgery, carries a risk of complications. Complications such as FBSS after spinal surgery are increasingly common. In retro- and prospective studies it has been estimated that about $3-14 \%$ of patients operated on for intervertebral disc pathology require reoperation $[10,11,12]$. This results from, among others, the greater number of spinal surgeries due to pain syndrome. Wilkinson revealed in his research that FBSS did not have to be associated with a complicated or failed surgical procedure. Pain syndrome may also develop after successful surgery and without intraoperative complications. Certainly, it develops more frequently when there are complications during the procedure, such as bleeding, nerve root injury or damaged dura mater structure [13]. The conducted studies showed that physiotherapy was one of the methods resulting in good therapeutic effects in the case of FBSS patients [14]. Furthermore, factors such as comorbidities, i.e. diabetes, hypertension, ischemic heart disease or stimulants, such as tobacco or alcohol, may be associated with the healing process of tissues after surgery, and may determine the time of recovery, especially in patients who underwent surgery.
The main purpose of this study was to assess the impact of smoking on back pain intensity in rehabilitated patients with discopathy, treated conservatively and surgically. A statistically significant $(\mathrm{p}<0.0469)$ negative impact of smoking on pain sensation (Laitinen scale) was observed in surgically treated patients.

Peolsson et al. (2003) showed a negative effect of smoking in patients treated surgically for cervical discopathy by cervical anterior spondylodesis [15]. McGregor and Hughes (2002) and Carragee and Kim (1997) found no negative impact of smoking on patients operated on due to spinal discopathy $[16,17,18]$. However, these studies were carried out on small groups of patients. Therefore, this issue requires further research and analyses.

Mekhail et al. (2018) presented a one-year follow-up in which current smokers reported a numerical rating scale pain score of 7.0, which is $1.93(\mathrm{p}<0.001)$ and $1.32(\mathrm{p}=0.001)$ points higher than those of lifelong nonsmokers and former smokers, respectively [19]. Robson et al. (2019) started a study with the aim of determining the effectiveness of a Healthy Lifestyle Programme (HeLP) for low back pain, targeting weight, physical activity, diet and smoking, to reduce disability in patients with chronic low back pain, compared with usual care. The outcomes of this trial and supplementary analyses will be disseminated through publications in peerreviewed journals and conference presentations [20].

It is worth mentioning that smoking has a negative impact on vascular endothelium which plays an important role in the regulation of: blood flow, blood pressure, synthesis and secretion of biologically-active factors, angiogenesis and immune responses. Smoking damages the vascular endothelium by disrupting its functions [21]. After spinal surgery, the circulatory system plays a key role in tissue healing; therefore, in smokers, when the vascular endothelium is damaged, the regeneration process after surgery is slower and less efficient, increasing the risk of complications. In smokers, the more extensive the surgery in which iatrogenic soft tissue damage occurs, the more impaired the regeneration process $[1,9,21]$.

\section{CONCLUSIONS}

1. Based on the obtained results, the following conclusions have been drawn:

2. Complex rehabilitation of patients with back pain syndrome due to discopathy demonstrates significant analgesic effectiveness.

3. Smoking significantly worsens the results of the therapy in patients who underwent surgery due to spinal discopathy.

\section{REFERENCES}

1. Kraemer J. Choroby krążka międzykręgowego [Intervertebral disc diseases]. Wrocław: Elsevier Urban \& Partner; 2012. In Polish.

2. Lama P, Le Maitre CL, Harding IJ, Dolan P, Adams MA. Nerves and blood vessels in degenerated intervertebral discs are confined to physically disrupted tissue. J Anat. 2018; 233: 86-97. https://doi. org/10.1111/joa.12817

3. Koszela K, Krukowska S, Woldańska-Okońska M. [Back pain as a lifestyle disease]. Pediatr Med Rodz. 2017; 13(3): 344-351. https://doi. org/10.15557/pimr. 2017.0036 In Polish.

4. Czapiński J, Panek T, eds. [Social diagnosis 2015. Objective and subjective quality of life in Poland]. Contemp Econ. 2015; 9(4) [cited 2019 Oct 30]. 
5. Shiri R, Karppinen J, Leino-Arjas P, Solovieva S, Viikari-Juntura E. The association between smoking and low back pain: a meta-analysis. Am J Med. 2010; 123(1): 87.e7-35. https://doi: 10.1016/j.amjmed.2009.05.028 6. Pingot J, Pingot M, Łabecka M, Woldańska-Okońska M. [The Use of Saunders Lumbar Traction in Physiotherapy of Patients With Chronic Lower Back Pain]. Pol Med J. 2014; 36(215): 330-5. In Polish.

7. Thomas KC, Fisher CG, Boyd M, Bishop P, Wing P, Dvorak M. Outcome evaluation of surgical and nonsurgical management of lumbar disc protrusion causing radiculopathy. Spine. 2007; 32(13): 1414-22. https:// doi.org/10.1097/brs.0b013e318060a5d1

8. Koszela K, Krukowska S, Woldańska-Okońska M. [The assessment of the impact of rehabilitation on the pain intensity level in patients with herniated nucleus pulposus of the intervertebral disc]. Pol Med J. 2017; 42(251): 201-204. In Polish.

9. Boos N, Aebi M. Choroby kręgosłupa [Spinal disorders]. Warszawa: Medipage; 2016. In Polish.

10. Rajaee SS, Kanim LE, Bae HW. National trends in revision spinal fusion in the USA: patient characteristics and complications. Bone Joint J. 2014; 96-B: 807-816. https://doi.org/10.1302/0301-620x.96b6.31149

11. Kraemer R, Herdmann J, Kraemer J. Mikrochirurgie der Wirbelsaule. Stuttgart: Thieme; 2005.

12. Martin B, Mirza SK, Comstock BA, Gray DT, Kreuter W, Deyo RA. Reoperation rates following lumbar spine surgery and the influence of spinal fusion procedures. Spine. 2007; 32(3): 382-7. https://doi. org/10.1097/01.brs.0000254104.55716.46

13. Sebaaly A, Lahoud MJ, Rizkallah M, Kreichati G, Kharrat K. Etiology, evaluation, and treatment of failed back surgery syndrome. Asian Spine J. 2018; 12: 574-85. https://doi.org/10.4184/asj.2018.12.3.574
14. Koszela K, Krukowska S, Woldańska-Okońska M. [Impact of rehabilitation on the level of pain intensity in patients with field back surgery syndrome]. Pol Med J. 2017; 42(252): 252-255. In Polish.

15. Peolsson A, Hedlund R, Vavruch L, Oberg B. Predictive factors for the outcome of anterior cervical decompression and fusion. Eur Spine J. 2003; 12(3): 274-80. https://doi.org/10.1007/s00586-003-0530-2

16. McGregor AH, Hughes SP. The evaluation of the surgical management of nerve root compression in patients with low back pain: Part 1: the assessment of outcome. Spine. 2002; 1(27): 1465-70.

17. McGregor AH, Hughes SP. The evaluation of the surgical management of nerve root compression in patients with low back pain: Part 2: patient expectations and satisfaction. Spine. 2002; 1(27): 1471-6.

18. Carragee EJ, Kim DH. A prospective analysis of magnetic resonance imaging findings in patients with sciatica and lumbar disc herniation. Correlation of outcomes with disc fragment and canal morphology. Spine. 1997; 15(22): 1650-60. https://doi.org/10.1097/00007632199707150-00025

19. Shiri R, Karppinen J, Leino-Arjas P, Solovieva S, Viikari-Juntura E. The association between smoking and low back pain: a meta-analysis. Am J Med. 2010; 123(1): 87.e7-35. https://doi: 10.1016/j.amjmed.2009.05.028

20. Robson EK, Kamper SJ, Davidson S, et al. Healthy Lifestyle Program (HeLP) for low back pain: protocol for a randomised controlled trial. BMJ Open. 2019; 9(9): e029290. https://doi: 10.1136/bmjopen-2019-029290 21. Tomczyk M, Nowak W, Jaźwa A. [Endothelium in the physiology and pathogenesis of diseases]. Postępy Biochemii. 2013; 59(4): 357-364. In Polish. 